\title{
Migración México/Estados Unidos en la década de crisis
}

\author{
PATRICIA FORTUNY Y SHINJI HIRAI
}

\section{Mexico/United States Migration} in a Decade of Crisis

PATRICIA FORTUNY Centro de Investigaciones y Estudios Superiores en Antropología Social-Peninsular, Mérida, Yucatán, México mpfortuny@gmail.com

SHINJI HIRAI

Centro de Investigaciones y Estudios Superiores en Antropología Social-Noreste, Monterrey, Nuevo León, México shinjihirai@yahoo.com

Desacatos 46, septiembre-diciembre 2014, pp. 6-11
19 de noviembre de 1989, tras escuchar la conferencia de prensa en la que el gobierno de Alemania Oriental, entonces República Democrática Alemana, anunció que todas las restricciones para viajar al exterior habían sido retiradas, miles de habitantes de Berlín tanto del lado oriental como del occidental se dirigieron hacia el muro, cuya construcción había iniciado en agosto de 1961 para dividir Alemania en dos y establecer una barrera ideológica. Muchos jóvenes alemanes orientales brincaron las barreras fronterizas. Otros ciudadanos comenzaron a derribar el muro pedazo a pedazo con martillos y picos. Bajo la presión de la muchedumbre que llegó al muro, los puntos de control se abrieron.

La caída del muro de Berlín fue un acontecimiento histórico importante que no sólo detonó la reunificación alemana y representó el fin de la Guerra Fría, también simbolizó el inicio de una nueva era de la movilidad humana y la circulación de bienes e información más allá de las fronteras nacionales y las barreras ideológicas. Después de este evento, el término "globalización" empezó a enunciarse tanto en los medios de comunicación como entre académicos de disciplinas de las ciencias sociales para anunciar la expansión del capitalismo y el surgimiento de un mercado económico a nivel planetario, debido a la intensa circulación transnacional de personas, dinero, objetos e información. En su libro La tierra es plana. Una breve historia del mundo globalizado del siglo XXI, el escritor estadounidense Thomas Friedman (2006) señala el impacto de la caída del muro de Berlín en la globalización y sostiene que fue una de "las fuerzas que aplanaron la tierra" a finales del siglo xx, dado que el hecho "desató unas fuerzas que liberaron $[. .$.$] a todos$ los pueblos cautivos del Imperio Soviético [...] Inclinó la balanza del poder en el mundo entero a favor de quienes defienden un gobierno democrático, consensuado y orientado al libre mercado" (Friedman, 2006: 57-58).

En los años noventa del mismo siglo, la globalización se veía con optimismo, como un fenómeno que permitiría construir un mundo 
conectado en múltiples planos de la realidad, como un proceso de fortalecimiento de las interdependencias entre empresas, individuos e instituciones de países distintos y como una fuerza liberadora del Estado-nación. El interés creciente en el concepto de globalización en varias disciplinas de las ciencias sociales y la perspectiva más amplia, integral y ambiciosa de estudiar fenómenos y procesos que se extienden más allá de las fronteras nacionales coincidían de cierta manera con los nuevos enfoques analíticos que comenzaron a proponerse en los estudios de migración internacional.

Entre finales de la década de 1980 e inicios de la de 1990, varios investigadores de la migración internacional señalaron la importancia del enfoque en las redes sociales (Massey et al., 1991). Otros plantearon introducir la perspectiva transnacional para entender espacios, prácticas y realidades nuevos que los migrantes construían. Por ejemplo, Michael Kearney y Carlos Nagengast (1989) propusieron el concepto "comunidad transnacional" a través del estudio de los migrantes oaxaqueños en las regiones agrícolas de California. El mismo año Roger Rouse (1989) utilizó el concepto "circuitos migratorios transnacionales" para analizar los vínculos transnacionales entre Redwood City, California, y Aguililla, Michoacán. Por su parte, Nina Glick Schiller, Linda Basch y Cristina Szanton Blanc definieron el transnacionalismo como "los procesos por los cuales los inmigrantes construyen campos sociales que vinculan su país de origen con su país de asentamiento" y formularon la noción de "campo social transnacional" como nuevo espacio social que elaboran los migrantes en el contexto de la intensa circulación de personas, bienes e información en el mundo contemporáneo (Glick, Basch y Szanton, 1992: 1).

Sin embargo, durante la última década hemos sido testigos de acontecimientos y cambios relevantes en las "reglas del juego" en lo concerniente a la migración mexicana hacia Estados Unidos. Después de 12 años de la caída del muro de Berlín, un acontecimiento en Nueva York, una de las principales ciudades globales (Sassen, 1991), debilitó el sentimiento optimista y celebratorio sobre la percepción de la acelerada circulación de personas, capital, productos e información, y al mismo tiempo provocó un giro importante en las condiciones políticas de la movilidad humana transfronteriza en la primera década del nuevo milenio. El 11 de septiembre de 2001 dos aeronaves boing 767, el vuelo 77 de American Airlines y el 175 de United Airlines, ambos secuestrados por integrantes de la red yihadista $\mathrm{Al}$ Qaeda, se estrellaron contra las Torres Gemelas del World Trade Center en Nueva York. El atentado suicida del vuelo 175 y el derrumbe de las torres se transmitieron en vivo por múltiples medios visuales y causaron consternación a nivel mundial. Con la excepción del ataque japonés acaecido en Pearl Harbor en 1941, Estados Unidos experimentó por primera vez una agresión de gran magnitud en lo que es considerado el centro histórico del territorio para los estadounidenses. Sin embargo, en el caso de Pearl Harbor los atentados kamikaze no alcanzaron siquiera la costa oeste, fueron en el Océano Pacífico. Una de las razones por las que el ataque terrorista del 11/09 asombró al mundo y generó el terror en la frontera porosa fue que la ofensiva vino del interior de su propio territorio y fue perpetrado por enemigos que se encontraban dentro del país. De los extranjeros que participaron en este atentado terrorista y los dos avionazos en El Pentágono y Pensilvania 15 eran originarios de Arabia Saudita, dos de los Emiratos Árabes Unidos, uno de Egipto y otro de Líbano.

Los hechos mencionados constituyen el contexto histórico y la coyuntura que impidieron el progreso relativo de las negociaciones bilaterales para regularizar a los indocumentados. Después del 11 de septiembre del 2001 el asunto migratorio en Estados Unidos se transformó en un tema de seguridad nacional: las políticas migratorias y las medidas 
del control fronterizo se tornaron tan severas que contribuyeron al surgimiento de un ambiente social hostil contra los inmigrantes, no sólo en algunos estados fronterizos del suroeste del país, también en los llamados "nuevos destinos" de migrantes mexicanos. Algunas consecuencias colaterales de los procesos denominados "securitización de migración", "militarización de la frontera" y "criminalización de migrantes" en Estados Unidos han sido el incremento en el número de muertos y desaparecidos en el cruce fronterizo, la vulnerabilidad de los migrantes frente a abusos y violaciones de sus derechos humanos por parte de las autoridades y las organizaciones especializadas en el negocio del cruce fronterizo clandestino, así como el aumento de las detenciones y deportaciones de inmigrantes indocumentados. En 2008, Estados Unidos entró en una crisis económica que afectó seriamente a importantes sectores del mercado laboral en los que se alojaban numerosos trabajadores migrantes. Esta crisis ha impactado tanto en los flujos migratorios como en la oferta laboral y la condición de vida de los migrantes.

Por su parte, el lado sur de la frontera MéxicoEstados Unidos ha padecido eventos trágicos durante la última década, en particular el norte de México y las rutas migratorias tradicionales y nuevas. En el contexto de la guerra contra el narcotráfico iniciada en 2006, los migrantes indocumentados en tránsito por México y aquellos mexicanos con intención de cruzar la frontera con Estados Unidos fueron aun más vulnerables. Se han reportado cuantiosos casos de extorsión, secuestro y asesinato de migrantes indocumentados en tránsito por México. Los migrantes mexicanos también han sido víctimas de actos criminales y de la violencia que se experimenta en varias regiones del país. Con frecuencia se denuncian numerosos casos de desaparición de emigrantes mexicanos y centroamericanos que intentan cruzar la frontera hacia "el país del norte" de manera clandestina.
Como señala Alonso Meneses en este número de Desacatos, las múltiples crisis económicas y sociales de la última década y de las políticas antimigratorias han dado como resultado "un saldo migratorio neto cercano a cero en México en 2013". De igual manera, si en el pasado existieron, sobre todo durante los programas braceros, algunas medidas de protección, control y seguridad para el migrante, han desaparecido y se han reorientado en su totalidad a proteger la seguridad nacional del país receptor, lo que deja al migrante en condiciones cada vez más vulnerables y viola sus más elementales derechos humanos, como ha demostrado Philippe Bourgois (2009), entre otros analistas del tema.

Para entender los cambios de la última década ya no es suficiente la imagen de los migrantes que se mueven de un país a otro de manera constante, construyen y viven en los espacios sociales extendidos en más de dos países, como si las fronteras no existieran. En contraste con las imágenes positivas de la globalización que predominaron en la década de 1990, la primera década del siglo xxi muestra el lado oscuro de la globalización y evidencia que vivimos una era de injusticia y dolor para una parte importante de la humanidad. Los migrantes mexicanos y los habitantes de sus comunidades de origen, poblaciones con las que hemos trabajado y convivido a través de las investigaciones, han experimentado estos procesos y acontecimientos, que han impactado tanto a México como a Estados Unidos. ¿Cómo han vivido los migrantes mexicanos en Estados Unidos y sus familias en México la primera década del siglo xxi, periodo que quizá marque un cambio de la era de la globalización? ¿Cómo han enfrentado los migrantes, a nivel de organización y comunidad, los problemas y retos que surgieron en este nuevo escenario? ¿Cuáles son los nuevos patrones migratorios? ¿Cómo ha respondido el Estado mexicano a los cambios en las políticas migratorias y de control fronterizo estadounidenses? ¿Cuáles son los temas y enfoques de la migración internacional 


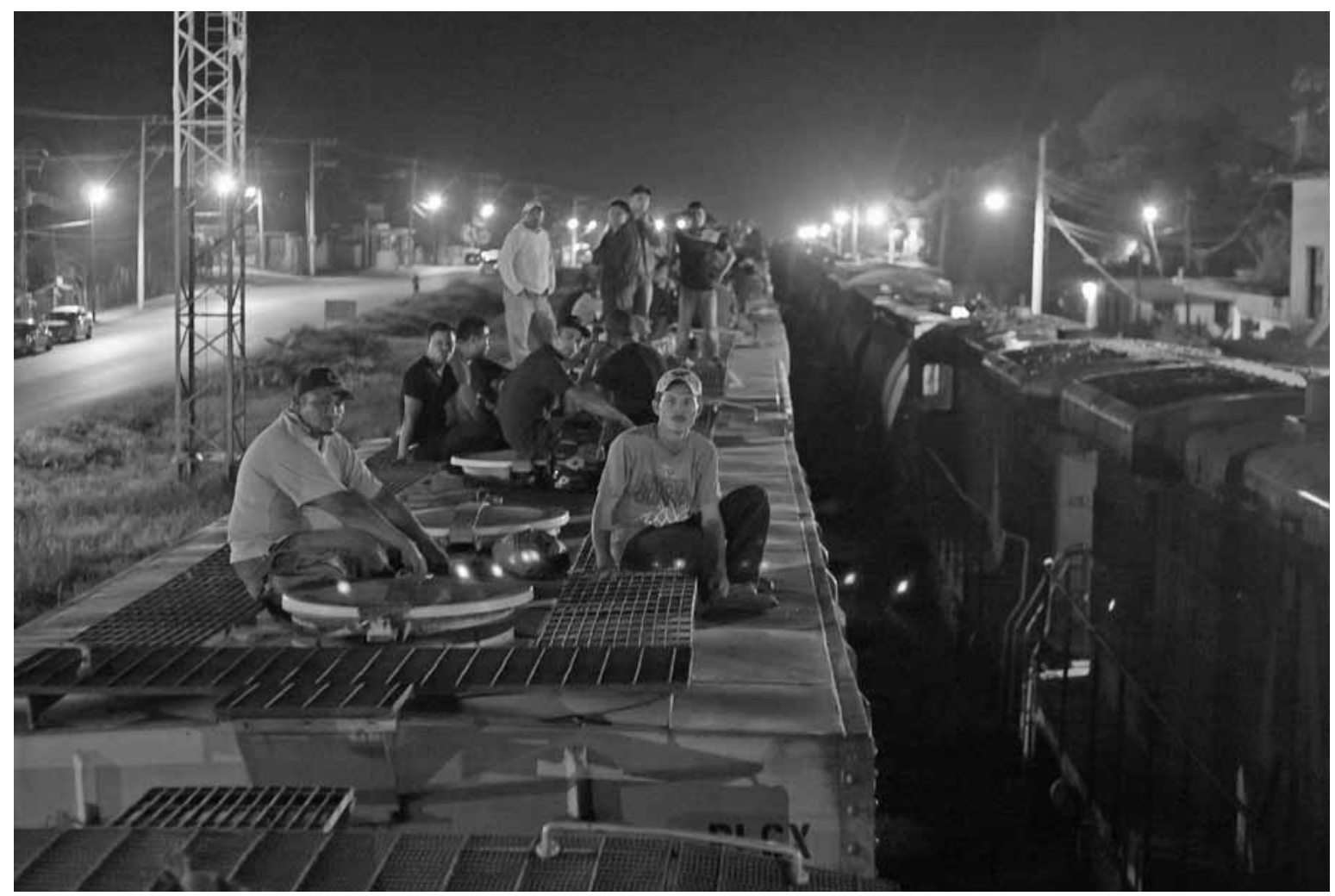

PROMETEO LucERo • Migrantes abordan el ferrocarril de carga, apodado "La Bestia”, en la estación ferroviaria de Tenosique, Tabasco.

que los especialistas han retomado para analizar las transformaciones de la última década en torno a la migración mexicana hacia Estados Unidos?

Antropólogos y sociólogos que han trabajado el tema de migración mexicana hacia Estados Unidos desde distintos enfoques fueron convocados en este número de Desacatos, que presenta un conjunto de textos orientado a analizar, explicar y comprender aquellos nuevos problemas sociales y desafíos que han experimentado las comunidades de migrantes mexicanos en Estados Unidos y sus lugares de origen en México durante la primera década del siglo XXI. Los investigadores que aportan sus trabajos a la sección "Saberes y razones" presentan nuevos aspectos del fenómeno migratorio y los cambios que han vivido tanto los migrantes como otros actores e instituciones, así como las reflexiones sobre los nuevos retos teóricos y metodológicos que han enfrentado los investigadores en la última década.

Guillermo Alonso Meneses es antropólogo y ha investigado el impacto de las políticas de control fronterizo estadounidense en las experiencias de los migrantes mexicanos. En su artículo hace un recuento de los operativos que el gobierno de Estados Unidos ha instrumentado desde los años noventa del siglo xx para controlar el flujo de migración irregular que atraviesa la frontera con México. Las detenciones masivas de migrantes cerca de la frontera, el levantamiento de nuevos muros, el aumento de la deportación de migrantes de largo arraigo y la desviación del flujo hacia los desiertos son algunas tendencias de estas medidas. Alonso Meneses señala que esta política de fortificación y militarización de la frontera ha tenido un impacto negativo en el 
respeto de los derechos humanos y civiles de los migrantes, que son más vulnerables que antes y se han convertido en blanco de estigmatización y violencia. A través del uso de la metáfora de "gulag", el autor argumenta que esta transformación del aparato del control fronterizo tiene una dimensión de limpieza étnica y de cirugía de extirpación socioeconómica cada vez más nítida.

Yerko Castro ha investigado la migración indígena hacia Estados Unidos y las comunidades mixtecas oaxaqueñas en California desde la antropología jurídica. Contribuye con una discusión acerca de la relación entre la política de "securitización" de la migración y la violencia contra los migrantes. ¿Cuáles son los nuevos signos y rasgos que definen la política y la violencia en los procesos de movilidad humana después del atentado terrorista del 11 de septiembre de 2001? ¿Por qué la política confeccionada en nombre de la securitización y la seguridad descansa en la violencia contra los migrantes y los viajeros subalternos? ¿De qué manera toda política de seguridad conlleva la producción múltiple y constante de inseguridades? ¿Por qué toda acción política que tiende a proteger y a cuidar la vida es al mismo tiempo una política que se enlaza y produce muerte? El autor presenta reflexiones innovadoras en torno a estas preguntas y propone una mirada crítica hacia las políticas de seguridad y de migración.

Luis Escala-Rabadán es sociólogo especializado en el estudio de las formas organizativas de los migrantes mexicanos en Estados Unidos. En su artículo presenta un panorama general sobre las formas asociativas de los clubes y federaciones de migrantes basados en la localidad o región de origen en México. Hace un recuento sobre la génesis y el desarrollo de estas asociaciones durante las últimas dos décadas. Asimismo, examina los logros de estas agrupaciones en su labor organizativa y algunos de los retos más importantes que enfrentan en fechas recientes. Para este autor la existencia de la densa red de agrupaciones de migrantes demuestra que la migración mexicana en Estados Unidos, conformada por individuos desposeídos y víctimas pasivas de estructuras omnipresentes, lejos de ser un fenómeno masivo y caótico, presenta una clara dimensión asociativa de diversos tipos, que hace posible la acción colectiva tanto en sus comunidades de origen como en los lugares de destino y la configuración de verdaderos espacios transnacionales. Escala-Rabadán sostiene que la pertenencia a asociaciones basadas en el pueblo de procedencia se convierte en un fuerte sentido de identidad colectiva y de empoderamiento para los migrantes. A la luz de una cada vez menor circulación de la población migrante entre México y Estados Unidos y una mayor tendencia hacia el establecimiento definitivo, estas asociaciones parecen incrementar su capacidad de funcionar como intermediarios efectivos en el proceso de promover un sentido de integración social entre los migrantes.

Patricia Fortuny Loret de Mola y Marie Friedmann Marquardt, antropólogas que trabajan la línea de investigación religiosidad y migración, analizan en su artículo dos parroquias en Atlanta, Georgia, que han registrado un crecimiento extraordinario de inmigrantes latinos entre sus feligreses y exploran las formas de adaptación de los migrantes a los cambios de la institución y de la comunidad. Ante la incapacidad del gobierno federal para aprobar la reforma migratoria, estados, condados y ciudades en todo el país han aprobado leyes con el objetivo no de reducir el flujo de migrantes, sino más bien de dificultar su asentamiento en un lugar dado. Georgia fue pionera en esta tendencia al aprobar en 2006 el Acta de Seguridad y Cumplimiento de las Leyes de Inmigración. En un ambiente antiinmigrante que impide una interacción pacífica y amable con los habitantes locales, las iglesias ofrecen uno de los espacios de relación interétnica. En los casos estudiados, la parroquia que sufre mayor tensión es la que ha impulsado más programas innovadores para 
promover la cooperación interétnica e iniciativas por la justicia de los migrantes. Las autoras describen el papel que juega la Iglesia católica como potencial mediador en las relaciones interétnicas tensas en la sociedad receptora.

El objetivo de publicar este conjunto de textos no es sólo difundir parte del conocimiento acumulado sobre el tema para informar al lector acerca de la multiplicidad de problemas que han enfrentado durante la última década los migrantes mexicanos que cruzan la frontera y/o radican en Estados Unidos, sino ayudar también a formar conciencia política y social sobre la gravedad del tema. $\mathbf{D}$

\section{Bibliografía}

Bourgois, Philippe, 2009, "Recognizing Invisible Violence. A Thirty-year Ethnographic Retrospective", en Barbara Rylko-Bauer, Linda Whiteford y Paul Farmer (eds.), Global Health in Times of Violence, School of Advanced Research Press, Santa Fe, pp. 18-40.

Friedman, Thomas, 2006, La tierra es plana. Una breve historia del mundo globalizado del siglo xxl, Martínez Roca, Madrid.

Glick Schiller, Nina, Linda Basch y Cristina Blanc Szanton, 1992, "Transnationalism: A New Analitic Framework for Understanding Migration", en Nina Glick Schiller, Linda Basch y Cristina Blanc Szanton (eds.), Towards a Transnational Perspective on Migration: Race, Class, Ethnicity and Nationalism Reconsidered, New York Academy of Sciences (Annals of the New York Academy of Sciences, núm. 645), Nueva York, pp. 1-24.

Kearney, Michael y Carole Nagengast, 1989, Anthropological Perspectives on Transnational Communities in Rural California, Working Group on Farm, Labor and Rural Poverty-California Institute for Rural Studies (Working Paper, núm. 3), California.

Massey, Douglas, Rafael Alarcón, Jorge Durand y Humberto González, 1991, Los ausentes. El proceso social de la migración internacional en el occidente de México, Alianza, Consejo Nacional para la Cultura y las Artes, México.

Rouse, Roger, 1989, “Mexican Migration to the United States: Family Relations in the Development of a Transnational Migrant Circuit”, tesis de doctorado, Departamento de Antropología-Stanford University, Stanford.

Sassen, Saskia, 1991, The Global City: New York, London and Tokyo, Princeton University Press, Princeton. 